\title{
Performance Analysis of Coal fired Power Plants in India
}

\author{
Santosh K Behera, and Ambika P Dash \\ NTPC, India \\ Jamal A Farooquie \\ Aligarh Muslim University \\ India
}

\begin{abstract}
With over $150 \mathrm{GW}$ of installed capacity and around 723.8 BUs of electricity generation during 2008-09, India remains the $5^{\text {th }}$ largest consumer of electricity in the world. Coal fired power plants account for more than half of the installed capacity and caters to more than $65 \%$ of the power demand. Against the prevalent practice of ratio analysis being used for the performance estimation, the study uses non-parametric Data Envelopment Analysis (DEA) to estimate the relative technical efficiency and scale efficiencies of coal-based power plants in India. It is found that the average technical efficiency of these plants is $83.2 \%$ with as many as 38 plants below the mean level. Distribution of the less efficient plants in different sectors, regions, their peer groups and the return to scale properties are analysed.
\end{abstract}

Keywords: Data Envelopment Analysis (DEA), Performance Evaluation, Power Generation, Coal fired thermal Power Plants.

\section{Introduction}

In spite of being the $5^{\text {th }}$ largest consumer of electricity in the world, with over $152 \mathrm{GW}$ of installed capacity (excluding captive generation) and 723.8 BUs of electricity generation during 2008-09, rapid growth of Indian economy witnessed in the recent years gets paralysed due to acute power shortage to the tune of $12.1 \%$ of peak deficit and $9.4 \%$ energy deficit. Ambitious target of providing electricity to the $44 \%$ of deprived Indian population with electricity, enhancing the per-capita consumption of electricity to $1000 \mathrm{KWH}$ from the current level of 704 $\mathrm{KWH}$, eliminate peak and energy shortage and provide spinning reserves of 5\% by 2012 envisioned in the National Electricity Policy -2005 (NEP) becomes a tough challenge for the energy planners. NEP also emphasizes on achieving higher efficiency of generating plants and increasing the $\mathrm{OAF}^{3}$ to $85 \%$. Coal fired power plants having slightly above $53 \%$ of the installed capacity contribute to more than $65 \%$ of the electricity generation. With electricity generation accounting for around $35 \%$ of the global energy related $\mathrm{CO}_{2}$ emissions, heavy dependence of India on fossil fuelled electricity generation and increasing demand for emission reductions, performance analysis of coal fired power plants becomes very important to mitigate energy shortage, reduce cost of generation and above all contain $\mathrm{CO}_{2}$ emissions. In addition electricity being the key ingredient for the socio-economic development of any country, productivity of the power generation sector has a strong bearing on the competitive advantage other sectors.

Current practice of performance measurement of the coal fired power plants, in the Indian context done by CEA ${ }^{2}$, involves ratio analysis in which set of ratios (input to output and output to input) like Plant Load Factor (PLF), Operational Availability Factor (OAF), Planned Maintenance (PM), Forced Outage (FO), Auxiliary Power Consumption (APC), Specific Coal Consumption (SCC) $)^{3}$ etc. are computed. These ratios indicate the partial factor productivity of the plants. With different indications being provided by these ratios interpretation becomes subjective leaving the managers to select their set of preferable ratios for decision making. Attempts made by CEA to aggregate the ratios to get a composite index based on predefined weight matrix for the ratios, again suffers from

\footnotetext{
${ }^{2}$ Central Electricity Authority, India - http://cea.nic.in

${ }^{3}$ PLF indicates the ratio of electricity generated to maximum possible generation, OAF, PM and FO indicates ratio of time for which unit was available, under planned maintenance and forced outage to total duration respectively. APC indicates the \%age of electricity consumed to power the auxiliary equipments and SCC indicates amount of coal consumed to generate one unit of electricity.
} 
subjective bias. This paper uses non-parametric Data Envelopment Analysis, to derive the optimal set of weight matrix from the observed dataset and estimate the relative performance level of these plants.

This paper is structured as follows: section II reviews literature on the application of DEA for performance measurement of production units in different sectors, energy and environmental studies and studies undertaken in the recent years to estimate the performance level of different segments of power sector in India. Section III provides a brief introduction to DEA followed by section IV where data and research methodology is discussed. Section IV analyses the results followed by Conclusion and Policy implications in Section V, limitations and scope for future study is detailed in section VI.

\section{Literature Survey}

Technical efficiency (TE) of a firm reflects its ability to minimize usage of inputs to produce a given amount of output. The firm, which uses the least input, is called technically efficient and has a TE score of $100 \%$. Since the seminal article by Charnes, Cooper and Rhodes (CCR model) followed by that of Banker, Charnes and Cooper (BCC model) to take care of variable return to scale, DEA had been used extensively used to estimate the relative efficiencies of homogenous production units ${ }^{4}$ producing similar outputs from identical inputs. To take care of diversities and complexities of the real world problems the basic CCR and BCC models has been augmented over years and the horizon of DEA has been extended from basic efficiency estimation to other areas like Policy Studies, Benchmarking , Exploring Virtual Mergers, Comparison of Business Models and Site Selections etc. [1]. Emrouznejad, Parker and Tavares [2] provide an extensive study of DEA literature till 2007.

Numerous studies have been reported in the literature studying the performance level of power utilities of USA, UK, Israel, India, Germany, Pakistan, Australia, Brazil and other countries in distribution as well as generation sector. Zhou, Ang and Poh [3] have surveyed application of DEA in energy and environmental studies. Making use of state of the art optimization and econometric techniques, several studies have been undertaken in the recent years to study the performance of Indian power utilities [4-8] also. Dash, Behera and Rath [9] while exploring alternative matrices for India's future power demand have observed that there is substantial scope for improvement of the performance of the thermal power plants and suggested for aggressive action plan for augmenting the current output levels. Behera, Mishra and Dash [11] have suggested a road map for enhancing the operational performance levels of the coal fired power plants and found that performance improvement of coal fired power plants alone has the potential to eliminate power shortage and a must along with capacity addition for supply side management of electricity in Indian scenario.

\section{Data Envelopment Analysis (DEA)}

DEA is a linear programming based, non-parametric technique extensively used primarily for performance measurement, target setting and bench marking of firms by academicians and practitioners worldwide. The primal version also called multiplier model, involves maximizing the ratio of weighted outputs to weighted inputs by assigning flexible weights to different inputs and outputs, subject to the restriction that the ratio for other firms remain within the bounds of 0 and 1 . The dual version also known as envelopment model involves carving out virtual firms from the linear combination of existing firms ${ }^{5}$ which consumes less input and produces more output. While the input oriented version of envelopment model aims at contracting the consumption of input levels to produce at least the same output, the output oriented one aims at augmenting the output levels with consumption of not more than the existing inputs levels. Cooper [1] provides excellent literature on various DEA models.

With $\mathrm{N}$ firms which consume $\mathrm{K}$ inputs to produce $\mathrm{M}$ outputs, $\mathrm{X}$ representing the input matrix of size $\mathrm{K} X \mathrm{~N}$ and $\mathrm{Y}$ representing the output matrix of size $\mathrm{MXN}$. $\mathrm{x}_{\mathrm{i}}$ and $\mathrm{y}_{\mathrm{i}}$ being the respective vectors for the $\mathrm{i}$-th DMU, $\theta$ a scalar and $\lambda$ a N X 1 vector of constants, the input oriented DEA model with variable return to scale is represented as:

\section{$\min \theta$}

\footnotetext{
${ }^{4}$ called decision-making units (DMUs) in DEA literature

${ }^{5}$ called peer groups
} 
$\theta, \lambda$

$\begin{array}{ll}\text { subject to } & \theta \mathrm{x}_{\mathrm{i}}-\mathrm{X} \lambda \geq 0 \\ & -\mathrm{yi}+\mathrm{Y} \lambda \geq 0 \\ & \Sigma \lambda_{\mathrm{i}}=1 \\ & \lambda_{\mathrm{i}} \geq 0\end{array}$

a. Data and Methodology: The installed capacity of coal/ lignite fired power plants increased from 64.95GW during 2003-04 to 76GW during 2007-08. We tried to include all the plants as on 200304, with the following exceptions. Plants commissioned after 2003-04 along with lignite fuelled power plants and those recorded no generation during the year were excluded from the study. We compiled the balanced panel of performance data of 74 plants over 5 years from 2003-04 to 200708 , which comprised of $83.9 \%$ (during 2007-08) to $88.5 \%$ (during 2005-06) of population. During the period capacity additions to the tune of $7.1 \mathrm{GW}$ took place. While 13 plants augmented their capacity by addition of new units, 2 plants shutdown their obsolete units during the period. Each plant in a different year was considered as a DMU resulting in 370 DMUs. Descriptive statistics of the different performance ratios is detailed in Table 1. Data compiled by CEA and published in their Review of Performance of Thermal Power Stations for different years [10] is used.

Table 1: Descriptive Statistics

\begin{tabular}{|l|r|r|r|r|r|}
\hline \multicolumn{7}{|c|}{} & $\mathrm{N}$ & Minimum & Maximum & \multicolumn{1}{c|}{ Mean } & Std. Deviation \\
\hline \multicolumn{7}{|c|}{ Output } \\
\hline Generation & 370 & 412.30 & 301908.60 & 62394.8926 & 56578.02569 \\
\hline \multicolumn{7}{|c|}{ Input } \\
\hline Capacity & 370 & 50.00 & 3260.00 & 811.3514 & 622.11131 \\
\hline PM & 370 & .00 & 82.77 & 8.7711 & 10.63771 \\
\hline FO & 370 & .06 & 62.75 & 10.6369 & 11.84088 \\
\hline SCC & 370 & .46 & 1.28 & .7433 & .12611 \\
\hline APC & 370 & 5.34 & 18.14 & 9.5524 & 1.98139 \\
\hline
\end{tabular}

Since scale information is lost in the ratios, to account for the scales of operation, annualized values of these parameters during a year is used in the analysis.

b. Inputs and Outputs: While power generated is the key output of these plants, coal consumed, capital cost of the plants and maintenance expenditure constitute the key inputs. In addition the amount electricity consumed by the power plants to power the auxiliaries (APC) is considered as a deemed input. As the power plants are built over years with the oldest coal fired unit commissioned on 31-11-1949, getting explicit capital cost of the plants is neither possible nor relevant. Capacity is considered as a proxy for capital cost. Maintenance expenditure of power plants is incurred broadly on account of periodic planned maintenance (PM) and unforeseen rapid maintenance owing to unscheduled forced outage (FO). Separate expenditure on these accounts is not maintained by many utilities. Based on the discussion with industry experts, it is gathered that loss of deemed generation due to PM and FO may be considered as a proxy for maintenance expenditure under these heads. The amount of coal consumed during a year is aggregated by multiplying the SCC with power generation and the electricity consumed by the power plants to power the auxiliaries (APC) is aggregated over a year. While power generated is the sole output, there are 5 inputs viz. Capacity, Coal consumed, APC consumed and deemed generation loss due to PM and FO. The manager aims at contracting the input levels and augmenting the output levels. 
c. Methodology: With the primary objective of the study to estimate excess consumption of inputs, the study uses input oriented variable return to scale model. In addition to possible reduction in cost of generation, reduction in SCC, APC, PM and FO will also lead to enhance the net power available to the grid and reduce $\mathrm{CO}_{2}$ emissions.

\section{Results}

Efficiency Scores: The results indicate as many as 49 DMUs occupy the efficient frontier defined by the operational parameters Capacity, PLF, SCC, APC, PM and FO. Some of the DMUs were actually the same firm in a different period reducing to the efficient DMUs to within 16. The mean technical efficiency taking in to account variable return to scale is $83.29 \%$ with the TE of as many as 174 of the 370 DMUs below mean TE. The technical efficiencies of the DMUs are depicted in Figure 1. While for 10 plants the average TE exceeds the average Scale Efficiency (SE), for remaining 64 plants the SE is more than the TE. While only two plants are consistently scale efficient during the five years, remaining 72 plants are scale inefficient. Only two plants are found to have technically efficient but scale inefficient during all the five years.

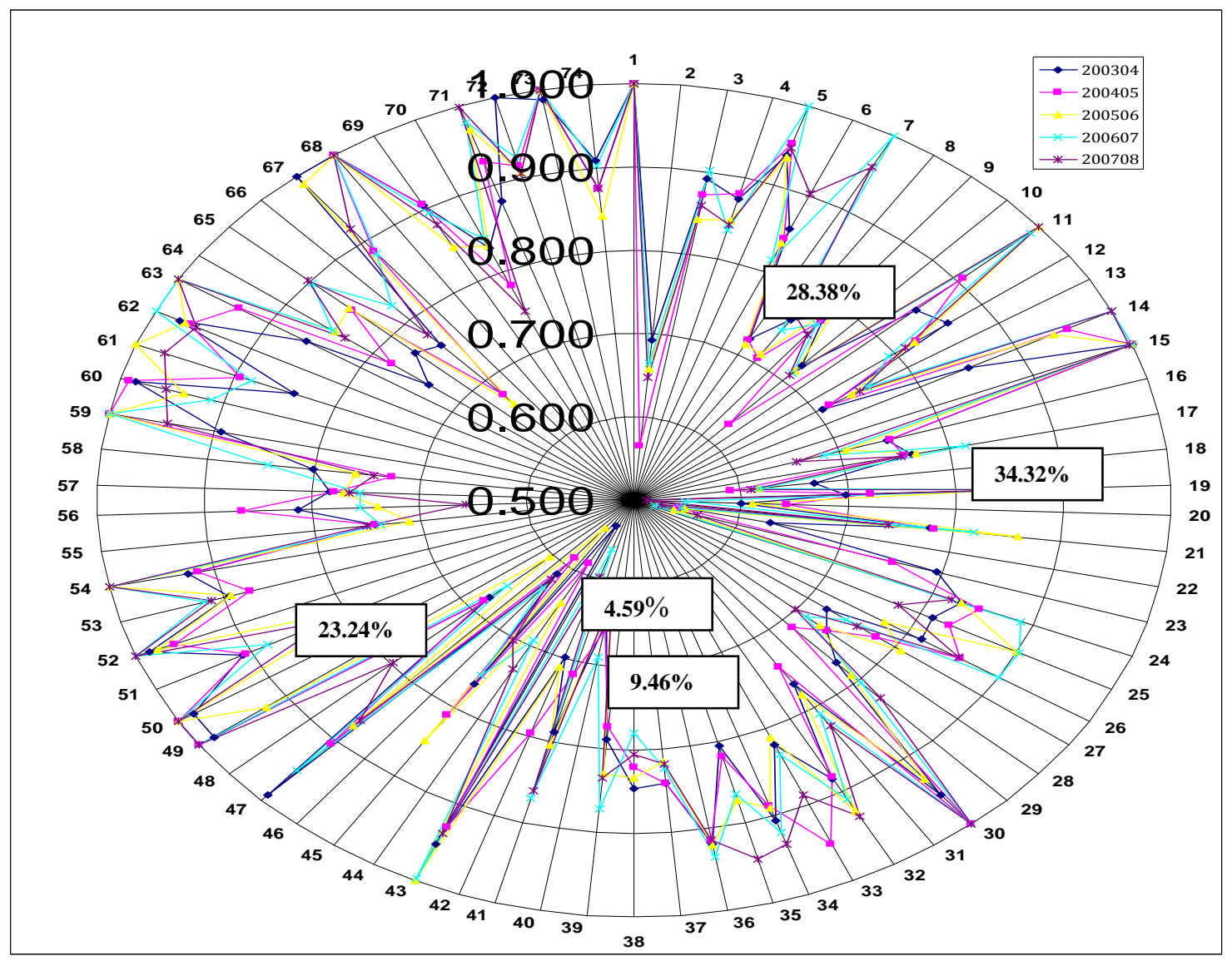

Figure 1: Efficiency Scores of plants in different years.

Peer Groups: For as many as 277 DMUs, it is possible to create hypothetical DMUs from the linear combination of DMU 15 and other DMUs which consumes less input and produces at least the same output as that of the real firm. The peer count of DMU 15 is highest. It is observed that DMU 15 in the year 2006-07 is viewed as a peer by as many as 226 other DMUs. DMUs in 2005-06 and 2006-07 appears as reference units very often while those in 2003-04 and 2004-05 appears less frequently. The frequency of occurrence of a plant as a peer in different periods is shown in Figure 2. 


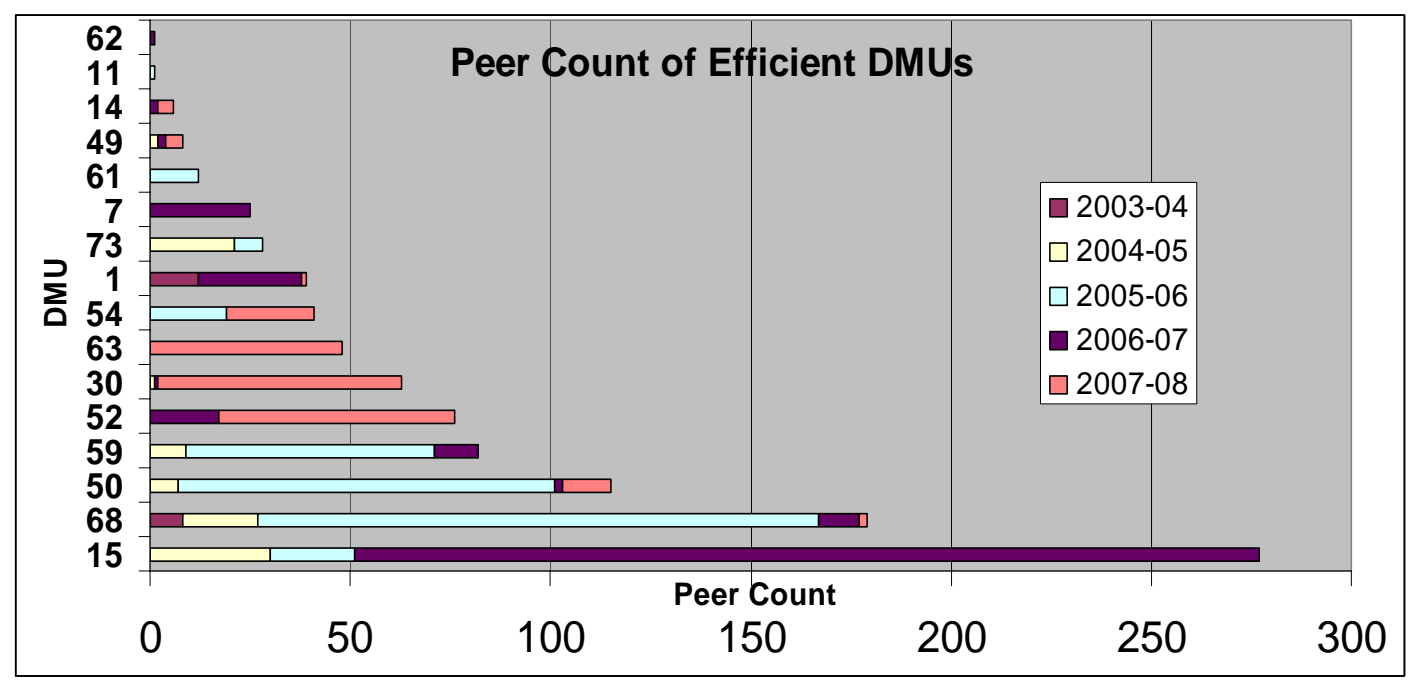

Figure 2: Frequency of Occurrence of a plant as Peer in different years.

Return to Scale (RTS): Out of the 74 plants spanned over 5 years, it is observed as many as 26 power plants exhibit increasing return to scale while 21 plants decreasing return to scale. While 2 plants show constant return to scale, the return to scale of remaining 25 other plants exhibit mixed trend during different periods. Sector wise RTS of DMUs is shown in Figure 3.

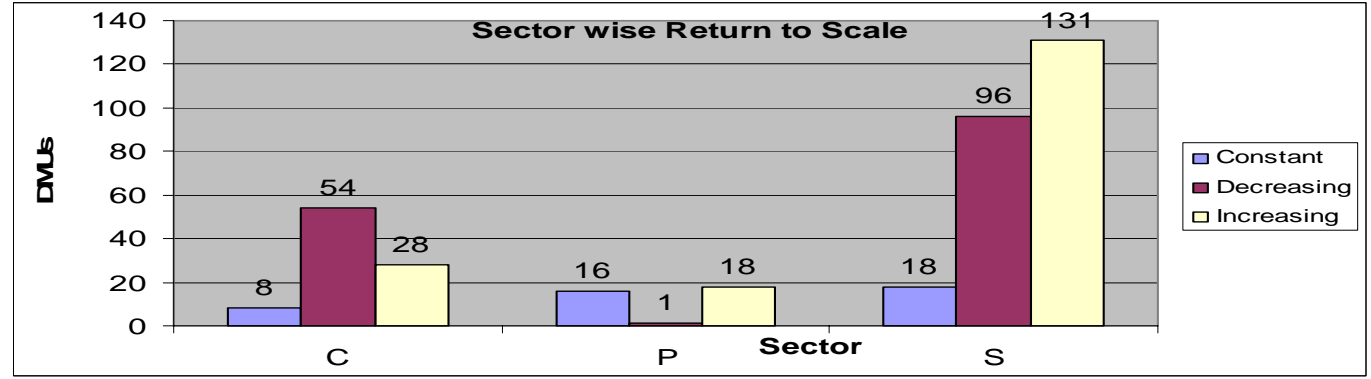

Figure 3: Sector wise Return to Scale

\section{Conclusion}

In contrast to conventional ratio analysis, which provides partial productivity measures, DEA approach not only provides a comprehensive efficiency measure but also quantifies the amount of slack which can be contracted without deteriorating the current level of output and identify peer units whose performance can emulated to eliminate the slacks. The study revealed that the TE of around $47 \%$ of DMUs and average TE of almost $50 \%$ plants lie below the mean TE. Two DMUs were occupying the efficiency frontier during all five years. Capacity slack is estimated to be $18.06 \%$ (about $10 \mathrm{GW}$ ). Even though it is not possible to contract the installed capacity, it indicates existing generation could be augmented further. This indicates substantial reduction of the operational parameters is possible and can be achieved by performance benchmarking of relevant best practices of efficient units. Reduction of PM and FO will increase the availability of the power plants and help attain higher PLF leading to more generation. Reduction in APC levels will make available more energy available to the grid. Reduction in SCC will lead to lesser consumption of coal and the scarce fossil fuels can be made available to other coal starved power plants which routinely suffer from loss of generation due to coal shortage. All these will lead to achieve the broader goal of making available more energy at a reduced cost of generation with reduce $\mathrm{CO}_{2}$ emissions. We hope the study will help setting realistic targets for the less efficient plants based on actual achievements by other plants and not on 
theoretical estimates. In the recent years, Indian power generation sector has seen several policy interventions in the form of Partnership in Excellence (PIE) and Rashtriya Sam Vikas Yojna (RSVY) by Govt. of India. Substantial performance improvement of few power plants like Unchahar, Talcher Thermal and Tanda have been recorded in the recent years by infusion of improved management practices by handing them over to NTPC, the biggest power generator in India by respective state governments. The study provides a robust performance management framework which can be leveraged to set and achieve unit / plant specific SMART targets and be used for the performance improvement of the power generating units / plants. The study could be further extended to unit level performance analysis and target setting by treating individual units as DMUs.

\section{Limitations and Scope for Future Research}

Even though theoretically it is possible for all the less efficient DMUs to move towards the efficient frontier by way of contraction of the consumed inputs and augmentation of produced outputs, practically every thing is not within the management control because of the different operating environments. Certain amount of inefficiency is attributed to the environmental variables under which the DMUs operate like the different management practices of different sectors/ operators, geographical locations and vintage of power generating units. The study could be extended further by taking into account these uncontrolled environmental variables, to analyse their impact to assist appropriate policy/managerial intervention.

\section{Acknowledgements}

The first and second author would like to express their thanks to NTPC Ltd and Prof A Tripathy, Dean VGSOM, IIT Kharagpur for the support and guidance extended to undertake a more detailed and elaborate unit level performance analysis of selected power plants.

\section{References}

1. Cooper, W.W., Seiford, L.M. and Tone, K., 2007, Data envelopment analysis: a comprehensive text with models, applications, Springer Science + Business Media LLC, New York, USA.

2. Emrouznejad, A., Parker B and Tavares G., 2008, "Evaluation of research in efficiency and productivity: A survey and analysis of the first 30 years of scholarly literature in DEA", Journal of Socio-Economics Planning Science, 42(3) 151-157.

3. Zhou, P., Ang, B.W. and Poh, K.L., 2008, "A survey of Data Envelopment Analysis in energy and environmental studies", European Journal of Operational Research, Vol. 189, Issue 1 PP 1-18.

4. Chitkara, P.,1999, "A data envelopment analysis approach to evaluation of operational in efficiencies in power generating units: A case study of Indian power plants", IEEE Transactions on Power Systems, Volume 14, No. 2, pp 419-425.

5. Shanmugam, K.R. and Kulshreshtha, P., 2005, "Efficiency Analysis of Coal Based Thermal Power Generation in India During the Post Reform Era", International Journal of Global Energy Issues, Vol. 23, No. 1, pp.15-28.

6. Nag, B., 2006, "Estimation of carbon baselines for power generation in India : the supply side approach", Energy Policy, vol. 34, no12, pp. 1399-1410.

7. Thakur, T., 2007, "Performance Evaluation of Electric Supply Utilities in India", PhD Dissertation, IIT Delhi.

8. Bhatiani, G., 2008, "Economic Efficiency Determination for pricing in Select Electricity distribution Companies in India", PhD Dissertation, University of Delhi, India.

9. Dash, A.P., Behera, S.K., and Rath, B.P., 2008, "Alternative matrices for India's future power Demands", Atoms for Peace, Volume 2, Number 1.

10. Review of Performance of Thermal Power Stations (2004 to 2008), Central Electricity Authority, India.

11. Behera, S.K., Mishra, A.K., and Dash, A.P., 2009, "Power Deficit: A Supply Side Management Perspective", Electrical India (Submitted). 